Archives of Agriculture and Environmental Science

\title{
Impacts of rainfall and temperature variation on maize (Zea mays L.) yields: A case study of Mbeya Region, Tanzania
}

\author{
Peter Batho ${ }^{1^{*}}$, Nyimvua Shaban ${ }^{1}$ and Agnes Mwakaje ${ }^{2}$ \\ ${ }^{1}$ Department of Mathematics, University of Dar es Salaam, TANZANIA \\ ${ }^{2}$ Institute of Resource Assessment, University of Dar es Salaam, TANZANIA \\ 'Corresponding author's E-mail: bathomaballa@gmail.com
}

\section{ARTICLE HISTORY}

Received: 14 April 2019

Revised received: 15 May 2019

Accepted: 25 May 2019

\section{Keywords}

Maize (Zea mays L.)

Mbeya region

Rainfall

Regression model

Tanzania

Temperature

Yields

\begin{abstract}
Based on the multiple regression model the impacts of rainfall and temperature on maize (Zea mays L.) yields in Mbeya region have been analyzed. Overall, findings revealed that the seven selected variables, that is, January maximum temperature, February maximum temperature, April maximum temperature, Rainfall from February to April, Rainfall during growing season, December rainfall and October maximum temperature influenced maize yields in the region by $65.4 \%$. Diversely, the results showed $34.6 \%$ wasn't explained by the model, meaning that there are other factors apart from temperature and rainfall could be used to explain the variation of maize (Z. mays) yield in the region. Furthermore, taking $1990-2012$ as baseline period, the model projection for a period of 2020-2042 shows that maize (Z. mays) yield may change from $1.5 \%$ to $2.3 \%, 2.6 \%$ to $3.6 \%$ and $2.4 \%$ to $3.5 \%$, as a result of separate future influence of $10 \%$ decrease in rainfall, $1^{\circ} \mathrm{C}$ raise in temperature and combined influence of both temperature and rainfall change, respectively. Nevertheless, the findings from this study, reveals that Mbeya region may still be potential maize (Z. mays) growing region in the prescribed period provided the magnitude change of both future rainfall and temperature hold and other factors not explained by the model do not change significantly. Therefore, the government must focus to conduct more research on uses of appropriate maize (Z. mays) varieties to obtain the maximum maize (Z. mays) crop yield in the region.
\end{abstract}

(C)2019 Agriculture and Environmental Science Academy

Citation of this article: Batho, P., Shaban, N. and Mwakaje, A. (2019). Impacts of rainfall and temperature variation on maize (Zea mays L.) yields: A case study of Mbeya Region, Tanzania. Archives of Agriculture and Environmental Science, 4(2): 177-184, https://dx.doi.org/10.26832/24566632.2019.040208

\section{INTRODUCTION}

A better understanding of the impacts of climate change and variability on crop yields to a stakeholder in the agricultural sector is of vital importance for proper planning in farming practices. One of the useful ways in enhancing such understanding is the use of models related results. Statistical and process based models are prominent in anticipating the effects of climate change and variability on crop production. Process based models usually simulate crop responses to specific weather, soil, management and crop factors governing agricultural productivity (White et al., 2011). Despite of their contribution in examining the effects of climate change on agricultural productivity, there are some limitations associated to these models. For instance, the models are calibrated for individual sites and are assumed to be accurate to simulate crop responses over that particular site (Lobell and Field, 2007). Furthermore, the scarcity of reliable data on weather, soil and management limits the use of models as an extensive predictive tool in evaluation as well as for planning and thus models have ended up providing only 'best-guess' estimates (Jones et al., 2003; Schlenker and Roberts, 2009). Statistical models employ historical data on crop yields and climate to develop statistical relationships. The main advantages of these models are on their limited dependence on field calibration data, transparence during model uncertainties assessment through the use of coefficients of determination and confidence intervals as well as their usefulness at large spatial scales. However, absence of adaptation responses in examining 
the future crop response projection is one of the limitations of statistical models; for instance, changes in varieties grown, planting and harvesting dates, and so on, are not taken into account (Lobell and Burke, 2010).

Different studies conducted to investigate the impact of climate change on crop production in Tanzania have reported mixed relationship between climate change and variability on crop production. Lema et al. (2014) reported the existence of positive relationship between rainfall and maize and beans; and negative relationship between temperature and maize and beans. Haji (2013) identified a positive correlation between rainfalls, mean minimum temperature and maize yield, but maximum temperature showed a negative relationship. Mongi et al. (2012); Mndeme (2016) and Majule (2015) reported that climatic variables, especially change of rainfall and temperature lead to the reduction of crop production. Rowhani et al. (2011), applied CERES (Crop Environment Resource Synthesis) model to examine the ability of statistical models to predict yield responses to changes in mean temperature and precipitation. The results reveal that both models projected maize yields decrease. This study assesses the impacts of rainfall and temperature variation on maize yields in Mbeya region in Tanzania using multiple regression model. The choice of the model is linked to the availability and nature of the data as well as transparence in assessing the model. Mbeya region is chosen as a case study area because; the region is the biggest maize producer in the country (URT, 2007). Maize (Zea mays L.) in the region as well as in the country is a major staple food, most marketed crop, and determinant of the national maize surplus. Furthermore, to the best knowledge of authors, there is no single study which has been conducted in the study area to assess the combined future impacts of rainfall and temperature variation on maize (Z. mays) yields using multiple regression models.

\section{MATERIALS AND METHODS}

\section{Collection of data}

The secondary data used in this study were collected from the Ministry of Agriculture and Cooperatives, Ministry of
Livestock and Fisheries Development and Tanzania Meteorological Agency (TMA). The meteorological and maize (Zea mays L.) yield data included monthly rainfall and rainfall during growing season, minimum and maximum temperatures as well as maize (Z. mays) yields in Mbeya region. Time series data (1990 -2012) covered 23 years were used for this study. Table 1, shows the variables used in the study, namely, observed maize (Z. mays)yields (OMY) as response variable and explanatory variables were January maximum temperature (Tjanmax), February maximum temperature (Tfebmax), April maximum temperature (Taprmax), Rainfall from February to April (Rfa), Rainfall during growing season (Rgs), December rainfall (Rdec) and October maximum temperature (Toctmax). Table 1, shows the climatic and maize (Z. mays) yields data used in the study area.

\section{About the study area}

Mbeya region lies between latitude $7^{\circ}$ and $9^{\circ} 31^{\prime}$ south of the equator and between longitude $32^{\circ}$ and $35^{\circ}$ east of Greenwich. The region lies at an altitude of 500 metres above sea level with high peaks of 2981 metres above sea level at Rungwe higher attitudes. The region shares borders with countries of Zambia and Malawi to the South; Rukwa Region to the West; Tabora and Singida Regions to the North; while Iringa region lies to its East (URT, 2007). In 2015 Mbeya region was divided into two regions of Mbeya and Songwe. The region usually receives rainy from October to May ranging from $650 \mathrm{~mm}$ to $2600 \mathrm{~mm}$ per annual while dry season starts from June to September. The region also experiences the temperatures range from about $16^{\circ} \mathrm{C}$ in the highlands to $30^{\circ} \mathrm{C}$ in the lowland areas (Figure 1) (URT, 2007).

Southern highland zone in the major maize (Z. mays) producer, accounting for about $33 \%$ of the total maize production in the country. Mbeya region alone accounts for $11 \%$ of the maize produced in the zone (AGPTAP, 2015). Maize (Z. mays) in Mbeya region is both a major staple food and most marketed crop (in volume terms). This being the case, maize (Z. mays) is of vital importance to the region considering its level of production as well as an important determinant of the national maize surplus.

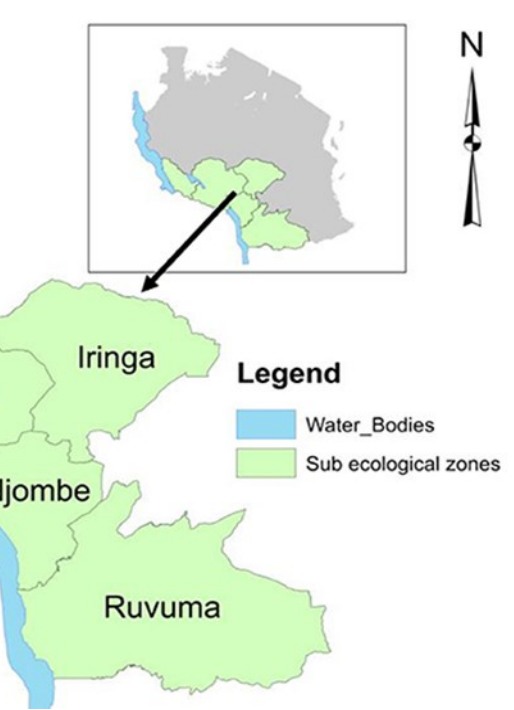

Figure 1. Depicts major maize production regions in Tanzania, including the study area (Source: Luhunga, 2017). 
Table 1. Depicts the climatic and maize (Z. mays) yields data used in the study.

\begin{tabular}{|c|c|c|c|c|c|c|c|c|}
\hline Year & $\begin{array}{c}\text { OMY } \\
\text { (tanne/ha) }\end{array}$ & $\begin{array}{c}\text { Tjanmax } \\
\left({ }^{\circ} \mathrm{C}\right)\end{array}$ & $\begin{array}{l}\text { Tfeb } \\
\left({ }^{0} \mathrm{C}\right)\end{array}$ & $\begin{array}{c}\text { Taprmax } \\
\left({ }^{\circ} \mathrm{C}\right)\end{array}$ & $\begin{array}{l}\text { RFA } \\
(\mathrm{mm})\end{array}$ & $\begin{array}{l}\text { RGS } \\
(\mathrm{mm})\end{array}$ & $\begin{array}{l}\text { Rdec } \\
(\mathrm{mm})\end{array}$ & $\begin{array}{c}\text { Toctmax } \\
\left({ }^{0} \mathrm{C}\right)\end{array}$ \\
\hline 1990 & 1.80 & 23.2 & 23.7 & 23.6 & 318.5 & 697.5 & 202.4 & 27.4 \\
\hline 1991 & 1.90 & 23.2 & 24.5 & 23.5 & 390.5 & 797.2 & 215.8 & 25.6 \\
\hline 1992 & 2.40 & 24.1 & 23.8 & 23.5 & 390.1 & 768.9 & 137.8 & 26.8 \\
\hline 1993 & 1.70 & 22.6 & 23.2 & 23.1 & 428.9 & 846.3 & 20.4 & 26.6 \\
\hline 1994 & 1.70 & 23.9 & 22.9 & 23.0 & 446.9 & 826.2 & 110.8 & 26.7 \\
\hline 1995 & 1.70 & 23.7 & 23.1 & 23.3 & 507.3 & 881.5 & 106.6 & 27.6 \\
\hline 1996 & 1.70 & 23.6 & 23.0 & 23.2 & 504.2 & 1061.9 & 235.9 & 27.5 \\
\hline 1997 & 1.70 & 24.5 & 23.2 & 23.3 & 423.5 & 992.3 & 372.4 & 26.7 \\
\hline 1998 & 1.90 & 23.4 & 23.4 & 23.4 & 442.0 & 743.2 & 76.6 & 27.0 \\
\hline 1999 & 1.40 & 22.7 & 24.9 & 23.4 & 449.8 & 948.3 & 144.7 & 25.8 \\
\hline 2000 & 2.00 & 24.0 & 23.9 & 23.6 & 461.2 & 918.1 & 252.6 & 27.1 \\
\hline 2001 & 2.30 & 22.2 & 23.6 & 23.5 & 305.1 & 846.6 & 174.5 & 25.9 \\
\hline 2002 & 1.20 & 22.8 & 24.0 & 23.4 & 396.1 & 766.1 & 153.9 & 27.3 \\
\hline 2003 & 2.00 & 23.9 & 25.1 & 23.6 & 321.7 & 772.5 & 162.3 & 27.4 \\
\hline 2004 & 2.30 & 24.6 & 23.9 & 23.4 & 388.3 & 896.6 & 286.9 & 26.7 \\
\hline 2005 & 2.20 & 23.9 & 25.6 & 23.7 & 315.2 & 641.3 & 112.9 & 27.1 \\
\hline 2006 & 2.00 & 24.8 & 24.6 & 23.0 & 369.3 & 991.6 & 319.6 & 27.7 \\
\hline 2007 & 1.80 & 23.6 & 24.1 & 23.4 & 352.2 & 842.4 & 209.1 & 27.0 \\
\hline 2008 & 2.20 & 23.3 & 23.3 & 23.4 & 432.7 & 905.5 & 167.4 & 27.3 \\
\hline 2009 & 2.20 & 24.4 & 23.5 & 23.3 & 443.4 & 897.6 & 160.7 & 27.8 \\
\hline 2010 & 1.90 & 24.6 & 24.2 & 23.4 & 400.8 & 677.3 & 93.1 & 28.1 \\
\hline 2011 & 1.80 & 24.5 & 24.2 & 23.6 & 453.1 & 1058.4 & 356.3 & 27.3 \\
\hline 2012 & 1.80 & 24.4 & 25.4 & 23.6 & 283.1 & 695.4 & 187.3 & 28.2 \\
\hline
\end{tabular}

Regression model development

Model assumptions

In developing the multiple regression model to be used in predicting the impacts of future rainfall and temperature variation on maize ( $Z$. mays) yields in Mbeya region, we first check the assumptions for multiple linear regression model.

\section{Linearity assumption}

The linearity assumption requires that the relationship between the dependent variable and independent variables is linear. Garson (2012) suggests that a proper method detect linearity is to run regression analysis.

In this study, if there is a significant linear relationship between the independent variables (climatic variables), $x \mathrm{i}, \mathrm{i}=1, \ldots . . . ., 7$ and the dependent variable (maize yield), $y_{\mathrm{j}}, \mathrm{i}=1, \ldots ., 23$, the slope will not equal zero. The null hypothesis therefore states that the slope is equal to zero, and the alternative hypothesis states that the slope is not equal to zero. Table 2 indicates the results from analysis of variance for the test of goodness of fit of the model at significance level of $5 \%$.

Analysis of Variance (ANOVA) (Table 2) indicates that p-value $(0.011)<0.05$, in this case null hypothesis is rejected. The test provide evidence that the linear relationship between maize yields and January maximum temperature, February maximum temperature, April maximum temperature, rainfall from February to April, rainfall during growing season, December rainfall and October maximum temperature exists.
Normality assumption

Normality assumption considers that variables have normal distributions. When the variables are not normally distributed, they can distort relationships and significance tests (Osborne and Waters, 2002). Shapiro-Wilk test is useful in examining the normality assumption whereby comparison is done between pre -assigned significance level and Shapiro-Wilk Test value. Shapiro-Wilk test is used when the sample size is less than 2000 (Shapiro and Wilk, 1965). If the significance value of the Shapiro -Wilk test is greater than the pre-assigned significance level then the data is normal, and once it is below the pre - assigned significance level then the data significantly deviate from a normal distribution. The $\mathrm{p}$-values of dependent and independent variables using Shapiro -Wilk test are shown in Table 3.

The Shapiro - Wilk $\mathrm{p}$ - value for each variable is greater than 0.005 (Table 3). The test suggests that the residuals are approximately normally distributed, meaning that the normality assumption is met. Therefore the variables used in this study are normally distributed.

Independence of errors assumption

This assumption requires that the regression model errors are independent; that is, the error terms are uncorrelated for any two observations (Mooi and Sarstedt, 2011). DW test is a prominent statistic test used in testing for the occurrence of serial correlation between residuals. The value of DW statistics ranges between 0 and 4. DW value below 1.5 or larger than 2.5 indicates a problem. We apply DW to test this assumption. 
The model summary for this study indicates that the values of $R$, R square, Adjusted R square, Standard error of the estimate and DW are $0.809,0.654,0.493,0.2065$ and 1.953 respectively. The DW statistic is 1.953 which is between 1.5 and 2.5 , in this case the data is not autocorrelated, implying that independence assumption is met and errors associated with the data used in this study are uncorrelated.

\section{Homoscedasticity assumption}

Homo (equal) scedasticity (spread) is the assumption that the error variance denoted by is equal for all observations. On the other hand, heteroskedasticity is the violation of the homoscedasticity assumption. Gelfand (2013) asserts that when this happens, the OLS estimates become inefficient, the regular standard errors of these estimates are wrong, leading to incorrect inferences. According to Chong (1993) the assumption of homogenous variance of residuals is highly affected by outliers because of large residuals. In this study we use the Glejser test method which is applied by performing the regression analysis and use the absolute residuals from the regression to test for the heteroskedasticity assumption.

The multiple regression equation relating the residuals and the climatic variables is given by;

$\left|\hat{u}_{i}\right|=\delta_{0}+\delta_{1} X_{1}+\delta_{2} X_{2}+\ldots \ldots \ldots \ldots . . .+\delta_{k} X_{k}+e_{i}$

where, $\delta_{0}$ through $\delta_{k}$ are residuals parameters,

$X_{1}$ through $X_{k}$ are the explanatory variables, and $e_{i}, i=1,2, \ldots, k$ is an error term.

To test for heteroskedasticity, we have the following hypotheses:

$H_{0}: \delta_{0}=\delta_{1}=\delta_{2}=\delta_{3}=\delta_{4}=\delta_{5}=\delta_{6}=\delta_{7}=0$

$H_{1}: \delta_{i} \neq 0$, at least one of the $\delta_{i}$ 's is not equal to zero, for $i=1,2, \ldots ., 7$.

If the significant value of each of the explanatory variable is greater than the significant level ( $\alpha$ ), then, the null hypothesis is accepted (there is no problem of heteroskedasticity). On the other hand, if the significant value of each of the explanatory variable is greater than the significant level ( $\alpha$ ), the null hypothesis is rejected (there is problem of heteroskedasticity). The $p$ value (from Table 4) of each of the residual parameters $X 1$ through $X 7$ is greater than a preassigned significance level of 0.005 . This means that null hypothesis is accepted and heteroskedasticity is not a problem.

\section{Multicollinearity assumption}

By definition, multicollinearity is a situation in which there is an exact or nearly relation among two or more of the input variables (Hawking and Pendleton, 1983). If the explanatory variables are highly correlated may result into inappropriate model, erroneous conclusion and sometimes insignificant parameters with significant model (Vaughan and Berry, 2005; Hawking and Pendleton, 1983). The VIF is widely used to test the extent of multicollinearity. The variance inflation factor for variable $X_{i}$ is denote as $\mathrm{VIF}_{\mathrm{i}}$ and is defined by the equation $\mathrm{VIF}_{\mathrm{i}}=1 / 1-\mathrm{R}_{\mathrm{i}}^{2}$, where $\mathrm{R}_{\mathrm{i}}{ }^{2}$ is the multiple coefficient of determination for the regression. There is no formal VIF cut off value for examining the existence of multicolinearity but (Alauddin and Nghiemb, 2010), recommend the VIF cut off point of 10 , because a value greater than 10 is often used as an indication of potential multicollinearity problem.

The model

Suppose we denote $\mathrm{X} 1=$ Tjanmax (OC), X2=Tfebmax (OC), X3 =Taprmax (OC), X4=Rfa (mm), X5=Rgs (mm), X6 = Rdec (mm), $X 7=$ Toctmax $(0 C)$, and $Y$ represents maize yields (tonne/ha), then the Regression Model relating these variables may be written as:

This system of $n$ equations can be written equivalently in matrix format as:

$$
\begin{aligned}
& y=\beta_{0}+x_{1}+\beta_{2} x_{2}+\beta_{3} x_{3}+\beta_{4} x_{4}+\beta_{5} x_{5}+ \\
& \beta_{6} x_{6}+\beta_{7} x_{7}+\varepsilon \\
& \text { where, }
\end{aligned}
$$

$\beta_{0}$ is the intercept when all $\mathrm{x}$ are set equal to zero and $\beta_{1}$ through $\beta_{7}$ are regression coefficients population parameters. $\mathrm{x}_{1}$ thro ugh $\mathrm{x}_{7}$ are the explanatory variables and $\varepsilon$ is the random error (residual) compon ent.

Suppose $\mathrm{n}>\mathrm{k}$ observations are available, and $\mathrm{y}_{i}$ denotes the ith observed response and $x_{i j}$ denotes the ith observation of explanatory variable $\mathrm{x}_{j}$. Then, the classical linear regression model is given by:

$y_{i}=\beta_{0}+x_{1} x_{1 i}+\beta_{2} x_{2 i}+\ldots \ldots . .+\beta_{k} x_{k i}$
$+\varepsilon_{i}(i=1,2, \ldots . ., n)$

we can write the equation for each observation as a sytems of $n$ equations for the classical linear regression model (equation 2) as follows :

$$
\begin{aligned}
& \mathrm{y}_{1}=\beta_{0}+\beta_{1} \mathrm{x}_{11}+\beta_{2} \mathrm{x}_{12}+\ldots \ldots .+\beta_{\mathrm{k}} \mathrm{x}_{1 \mathrm{k}}+\varepsilon_{1} \\
& \mathrm{y}_{2}=\beta_{0}+\beta_{1} \mathrm{x}_{21}+\beta_{2} \mathrm{x}_{22}+\ldots \ldots .+\beta_{\mathrm{k}} \mathrm{x}_{2 \mathrm{k}}+\varepsilon_{2} \\
& \mathrm{y}_{\mathrm{n}}=\beta_{0}+\beta_{1} \mathrm{x}_{\mathrm{n} 1}+\beta_{2} \mathrm{x}_{\mathrm{n} 2}+\ldots \ldots .+\beta_{\mathrm{k}} \mathrm{x}_{\mathrm{nk}}+\varepsilon_{\mathrm{n}}
\end{aligned}
$$

This system of $\mathrm{n}$ equations can be written equivalently in matrix format as : 
$y=X \beta+\varepsilon$

where,

$\mathrm{y}$ is $\mathrm{n} \times 1$ vectors

$\beta$ is $m \times 1$ vectors and

$\mathrm{X}$ is $\mathrm{n} \times \mathrm{m}$ vectors.

where,

$\mathrm{m}=\mathrm{k}+1$ is the number of parameters.

Let $\beta$ be $k \times 1$ vector of estimates of $\beta$, then the estimated model (equqtion 3 ) may be written as :

$\mathrm{y}=\mathrm{X} \hat{\beta}+\mathrm{e}$

$\mathrm{e}$ is $n \times 1$ vector of residues, computed as :

$\mathrm{e}=\mathrm{y}-\mathrm{X} \hat{\beta}$

To determine the least square estimator, we write the sum of squares of the resi -

dues (a function of $\hat{\beta}$ ) as :

$\mathrm{S}(\hat{\beta})=\sum_{\mathrm{i}=1}^{\mathrm{n}} \mathrm{e}_{\mathrm{i}}^{2}=\mathrm{e}^{\mathrm{T}} \mathrm{e}=(\mathrm{y}-\mathrm{X} \hat{\beta})^{\mathrm{T}}(\mathrm{y}-\mathrm{X} \hat{\beta})$

The minimum of $\mathbf{S}(\hat{\boldsymbol{\beta}})$ is obtained by setting the derivatives of $S(\hat{\beta})$ equal to zero.

$$
\begin{array}{r}
\frac{S(\hat{\beta})}{S(\hat{\beta})}=-2 X^{\mathrm{T}} y+2 X^{\mathrm{T}} X \hat{\beta}=0 \\
X^{\mathrm{T}} \mathrm{y}=\mathrm{X}^{\mathrm{T}} \mathrm{X} \hat{\beta}
\end{array}
$$

Multiplying both sides of equation (7) by we have;

$$
\hat{\beta}=\left(X^{T} X\right)^{-1} X^{T} y
$$

$$
\text { Since } k=7 \text {, then } \hat{\beta}=\left[\begin{array}{l}
\hat{\beta}_{0}, \hat{\beta}_{1}, \hat{\beta}_{2}, \hat{\beta}_{3}, \hat{\beta}_{4}, \\
\hat{\beta}_{5}, \hat{\beta}_{6}, \hat{\beta}_{7}
\end{array}\right]
$$

Where, $\hat{\beta}_{0}, \hat{\beta}_{1}, \hat{\beta}_{2}, \hat{\beta}_{3}, \hat{\beta}_{4}, \hat{\beta}_{5}, \hat{\beta}_{6}$ and $\hat{\beta}_{7}$ are the estimators of $\beta_{0}, \beta_{1}, \beta_{2}, \beta_{3}, \beta_{4}$, $\beta_{5}, \beta_{6}$, and $\beta_{7}$ respectively.
The estimated coefficients of the model generate the predicted values given by;

$$
\begin{aligned}
& \mathrm{y}=\hat{\beta}_{0}+\hat{\beta}_{1} \mathrm{X}_{1}+\hat{\beta}_{2} \mathrm{X}_{2}+\hat{\beta}_{3} \mathrm{X}_{3}+ \\
& \hat{\beta}_{4} \mathrm{X}_{4}+\hat{\beta}_{5} \mathrm{X}_{5}+\hat{\beta}_{6} \mathrm{X}_{6}+\hat{\beta}_{7} \mathrm{X}_{7}+\varepsilon
\end{aligned}
$$

From table $6, \hat{\beta}_{0}=-23.716, \hat{\beta}_{1}=+0.499$,

$\hat{\beta}_{2}=-0.289, \hat{\beta}_{3}=+1.161, \hat{\beta}_{4}=-0.006$

$\hat{\beta}_{5}=+0.003, \hat{\beta}_{6}=-0.004$, and $\hat{\beta}_{7}=-0.219$.

Hence equation (8) becomes :

$$
\begin{aligned}
& Y_{\mathrm{i}}=-23.716+0.499 \mathrm{X}_{1 \mathrm{i}}-0.289 \mathrm{X}_{2 \mathrm{i}}+ \\
& 1.161 \mathrm{X}_{3 \mathrm{i}}-0.006 \mathrm{X}_{4 \mathrm{i}}+0.003 \mathrm{X}_{5 \mathrm{i}}- \\
& 0.004 \mathrm{X}_{6 \mathrm{i}}-0.219 \mathrm{X}_{7 \mathrm{i}}+\varepsilon
\end{aligned}
$$

Equation (9) represents the model that describes the relationship between maize yields and climatic variables.

\section{Testing the significance of the model}

To be sure that the model works well and produces reliable results, testing its siginificance is vital impor tance. The significanceof the model is tested by formula ting two hypotheses. The model hypotheses are stated below.

Null hypothesis

$\mathrm{H}_{0}: \beta_{1}=0 ;$ none of the explanatory variables is significant.

$\beta_{2}=\beta_{3}=\beta_{4}=\beta_{5}=\beta_{6}=\beta_{7}=$

Alternative hypothesis

$\mathrm{H}_{\mathrm{A}}: \beta_{\mathrm{i}} \neq 0$, for $\mathrm{i}=1,2,3,4,5,6,7$; at least one of the explanatory variables is not equal to zero.

From analysis of variance (ANOVA) (Table 2), the Test statistic equal to 4.051 and its corresponding $p$ - value $(0.011)$ is less than $5 \%$, implying that there is strong statistical evidence that at least one of the regression coefficient in non -zero. We use ttest to examine the significance of each (individual) explanatory variable. Since the $p$-value for each explanatory variable is less than 0.05 this implies that all climatic variables are non-zero. Therefore the developed model is significance. 


\section{RESULTS AND DISCUSSION}

We focus on results from the regression model in assessing the impacts of rainfall and temperature variations on maize ( $Z$. mays) yields in Mbeya region. We first show the predictive ability of the model by examining the coefficient of multiple determination and $\mathrm{p}$ - value in relation to the significance level. Then, we present the projection of the impacts of rainfall and temperature variation on maize (Z. mays) yields in the region in 2020 -2042 period, taking 1990- 2012 as the baseline period by considering the temperature increase of $1^{\circ} \mathrm{C}$ and rainfall decrease of $10 \%$ in the prescribed period. The choice of two climatic variable variations in future is based on result from climate models for Tanzania which project that future average annual temperature may increase between $1^{\circ} \mathrm{C}-3^{\circ} \mathrm{C}$, and the areas which receive uni modal rainfall seasons, could experience annual rainfall decrease of $5 \%-15 \%$ (United Republic of Tanzania, 2014).

\section{Goodness of fit of the model}

The result showed that predictive model for maize (Z. mays) yield was statistically significant with $\alpha \leq 0.05$ (Table 2 ). The value of $R^{2}=0.654$, indicating that $65.4 \%$ of the variation in maize (Z. mays) yield in Mbeya region is explained by the climatic variables. On the other hand, $34.6 \%$ could be attributed to other factors not captured by the model (Figure 2 ).

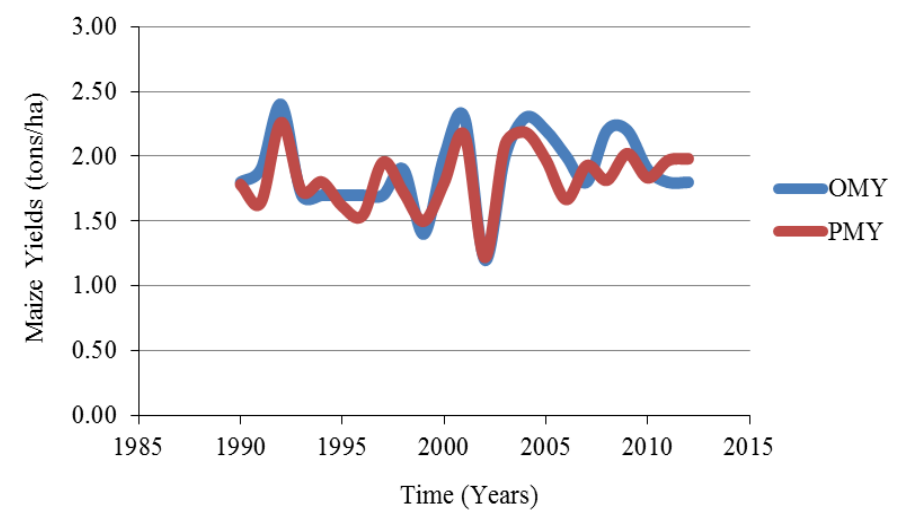

Figure 2. Observed maize (Z. mays) yields (OMY) and predicted maize yields $(P M Y)$ in tonne/ha in Mbeya region of Tanzania.
Maize yields change due to separate and combined future impact of rainfall and temperature

In this study, we consider the future rainfall decrease of $10 \%$ and $1^{\circ} \mathrm{C}$ increase in temperature to predict the separate and combine impact of both temperature and rainfall on maize (Z. mays) yields in Mbeya region. Lobell and Burke (2010) argue that time series models can extremely be useful for projections for the next 20-30 years. Therefore, taking $1990-2012$ as the baseline period, the study may predict the future influence of these climatic changes on maize (Z. mays) yields in 20202042 period taking the maximum projection of 30 years. Table 6, describes maize (Z. mays) yield change due to future separate and combined impact of rainfall and temperature variation.

Future impact of rainfall variation on maize (Z. mays) yield in Mbeya region

Considering the rainfall variable alone, the model indicates that the coefficients of total rainfall from February to April (Rfa), rainfall during growing season (Rgs) and December rainfall (Rdec) are $-0.006,+0.003$ and -0.004 , respectively. This being the case, Rfa and Rdec impact maize (Z. mays) yields negatively. Importantly, Rgs, rainfall during the growing season is positive and favours maize (Z. mays) yields in the region. Generally, the rainfall decrease of $10 \%$ may cause the maize (Z. mays) yields in Mbeya region to change between $1.5 \%$ to $2.3 \%$ in $2020-2042$ taking 1992 -2012 as baseline period. Baijukya et al. (2016) suggest that maize usually needs about $500 \mathrm{~mm}-1500 \mathrm{~mm}$ of rainfall per growing season although some maize types can do well with as little as $250 \mathrm{~mm}$ of rainfall. Examining the rainfall per growing season from the data, rainfall decrease of $10 \%$ may cause the rainfall during the growing season to fall into the range of $577 \mathrm{~mm}$ and $956 \mathrm{~mm}$ inclusive. Thus, such decrease in future may not have substantial impact on maize yields in prescribed period, provided other factors not explained by the model do not change significantly.

Table 2. Analysis of variance (ANOVA) for the test of goodness of fit of the model $\alpha=5 \%$.

\begin{tabular}{lccccc}
\hline Model & Sum of squares & Df & Mean square & F & Significance \\
\hline Regression & 1.210 & 7 & 0.173 & 4.051 & 0.011 \\
Residual & 0.640 & 15 & 0.043 & & \\
Total & 1.850 & 22 & & \\
\hline
\end{tabular}

Table 3. Depicts the P- values for dependent and independent variables for Shapiro- Wilk at $\alpha=5 \%$.

\begin{tabular}{lc}
\hline Variable & P-Value \\
\hline $\mathrm{Y}$ & 0.308 \\
$\mathrm{X}_{1}$ & 0.372 \\
$\mathrm{X}_{2}$ & 0.231 \\
$\mathrm{X}_{3}$ & 0.065 \\
$\mathrm{X}_{4}$ & 0.384 \\
$\mathrm{X}_{5}$ & 0.785 \\
$\mathrm{X}_{6}$ & 0.559 \\
$\mathrm{X}_{7}$ & 0.336 \\
\hline
\end{tabular}

Table 4. Depicts the $P$-value corresponding to the residual parameters $X_{1}$ through $X_{7}$ at $\alpha=5 \%$.

\begin{tabular}{ll}
\hline Variable & P-Value \\
\hline$X_{1}$ & 0.972 \\
$X_{2}$ & 0.154 \\
$X_{3}$ & 0.164 \\
$X_{4}$ & 0.631 \\
$X_{5}$ & 0.549 \\
$X_{6}$ & 0.590 \\
$X_{7}$ & 0.572 \\
\hline
\end{tabular}


Future impact of temperature variation on maize (Z. mays) yield in Mbeya region

Regarding the temperature variable, the model indicates that the increase of $1^{\circ} \mathrm{C}$ in $2020-2042$, maize (Z. mays) yields in Mbeya region may change between $2.6 \%$ to $3.6 \%$ (Table 6 ) taking $1990-2012$ as baseline period. This finding is in agreement with the result obtained by Mtongori et al. (2016). They found that increase in temperature favored maize yield in southern part of Tanzania for some cultivars. Importantly, Statistical studies have indicated that daily maximum temperature greater than approximately $30^{\circ} \mathrm{C}$ limit maize yields (Schlenker and Roberts, 2009; Lobell et al., 2011). Commuri and Jones (2001) found that temperatures above $30^{\circ} \mathrm{C}$ increasingly impaired cell division and amyloplast replication in maize kernels, and thus reduced grain sink strength and yields. This being the case, considering the temperature data used in this study, the maximum temperatures in the region will not be beyond $30^{\circ} \mathrm{C}$, implying that the future temperatures change in prescribed period by considering the increase of $1^{\circ} \mathrm{C}$ may still be in the limit that is suitable and not harmful for growing maize.

Future impact of combined variation on maize (Z. mays) yield in Mbeya region

The model results also indicate that the future combined effect of both temperature and rainfall may cause maize yields change between $2.4 \%$ and $3.5 \%$ in 2020 -2042, taking $1990-2012$ as the baseline period.

Table 5. Depicts unstandardized and standardized coefficients, $t$ and $p$-values and VIF of climatic variables.

\begin{tabular}{|c|c|c|c|c|c|c|}
\hline \multirow[t]{2}{*}{ Variable } & \multicolumn{2}{|c|}{$\begin{array}{l}\text { Unstandardized } \\
\text { coefficients }\end{array}$} & \multirow{2}{*}{$\begin{array}{c}\text { Standardized } \\
\text { coefficients }\end{array}$} & \multirow[t]{2}{*}{$\mathrm{T}$} & \multirow[t]{2}{*}{ Significance } & \multirow{2}{*}{$\begin{array}{c}\text { Collinearity statistics } \\
\text { VIF }\end{array}$} \\
\hline & $\mathrm{B}$ & Std. Error & & & & \\
\hline Constant & -23.716 & 8.482 & & -2.796 & 0.014 & \\
\hline $\operatorname{Tjanmax}\left(\mathrm{X}_{1}\right)$ & 0.499 & 0.110 & 1.242 & 4.521 & 0.000 & 3.273 \\
\hline $\operatorname{Tfebmax}\left(\mathrm{X}_{2}\right)$ & -0.289 & 0.088 & -0.763 & -3.280 & 0.005 & 2.349 \\
\hline Taprmax $\left(X_{3}\right)$ & 1.161 & 0.348 & 0.763 & 3.340 & 0.004 & 2.265 \\
\hline $\operatorname{Rfa}\left(X_{4}\right)$ & -0.006 & 0.001 & -1.220 & -3.939 & 0.001 & 4.159 \\
\hline $\operatorname{Rgs}\left(X_{5}\right)$ & 0.003 & 0.001 & 1.201 & 2.971 & 0.010 & 7.079 \\
\hline $\operatorname{Rdec}\left(X_{6}\right)$ & -0.004 & 0.001 & -1.281 & -3.460 & 0.003 & 5.941 \\
\hline $\operatorname{Toctmax}\left(X_{7}\right)$ & -0.219 & 0.088 & -0.507 & -2.495 & 0.025 & 1.793 \\
\hline
\end{tabular}

The VIF of all independent variables, that is, VIF of $X_{1}, X_{2}, X_{3}, X_{4}, X_{5}$ and $X_{6}$, and $X_{7}$ are less than 10 . This indicates the absence of multicollinearity and implies that variables are not highly correlated.

Table 6. Shows maize (Z. mays) yields change in Mbeya region due to future separate and combined impact of rainfall and temperature variation.

\begin{tabular}{|c|c|c|c|c|}
\hline Years & $\begin{array}{c}\mathrm{OMY} \\
\text { (tons/ha) }\end{array}$ & $\begin{array}{l}\text { Maize yields in \% due to } \\
\text { temperature rise by } 1^{0} \mathrm{C}\end{array}$ & $\begin{array}{c}\text { Maize yields change in \% due to temperature } \\
\text { rise of } 1^{\circ} \mathrm{C} \text { and rainfall decrease of } 10 \%\end{array}$ & $\begin{array}{l}\text { Maize yield change in \% due } \\
\text { to rainfall decrease of } 10 \%\end{array}$ \\
\hline 1990 & 1.80 & 3.2 & 3.0 & 1.8 \\
\hline 1991 & 1.90 & 3.0 & 2.9 & 1.7 \\
\hline 1992 & 2.40 & 3.6 & 3.5 & 2.3 \\
\hline 1993 & 1.70 & 3.1 & 2.9 & 1.7 \\
\hline 1994 & 1.70 & 3.2 & 3.0 & 1.9 \\
\hline 1995 & 1.70 & 3.0 & 2.9 & 1.7 \\
\hline 1996 & 1.70 & 2.9 & 2.8 & 1.6 \\
\hline 1997 & 1.70 & 3.3 & 3.2 & 2.1 \\
\hline 1998 & 1.90 & 3.1 & 2.9 & 1.8 \\
\hline 1999 & 1.40 & 2.9 & 2.7 & 1.5 \\
\hline 2000 & 2.00 & 3.2 & 3.0 & 1.9 \\
\hline 2001 & 2.30 & 3.5 & 3.3 & 2.2 \\
\hline 2002 & 1.20 & 2.6 & 2.4 & 1.3 \\
\hline 2003 & 2.00 & 3.5 & 3.3 & 2.1 \\
\hline 2004 & 2.30 & 3.6 & 3.4 & 2.3 \\
\hline 2005 & 2.20 & 3.3 & 3.2 & 2.0 \\
\hline 2006 & 2.00 & 3.0 & 2.9 & 1.7 \\
\hline 2007 & 1.80 & 3.3 & 3.1 & 2.0 \\
\hline 2008 & 2.20 & 3.2 & 3.0 & 1.9 \\
\hline 2009 & 2.20 & 3.4 & 3.2 & 2.1 \\
\hline 2010 & 1.90 & 3.2 & 3.1 & 1.9 \\
\hline 2011 & 1.80 & 3.3 & 3.2 & 2.1 \\
\hline 2012 & 1.80 & 3.4 & 3.2 & 2.0 \\
\hline
\end{tabular}




\section{Conclusion}

This study has demonstrated that multiple regression model might provide more insight on assessing the effects of rainfall and temperature variation on maize (Z. mays) yields at regional level. Since the model has revealed that change in temperature and rainfall may have impacts on maize (Z. mays) yields in the region, the following recommendations are useful: Factors other than temperature and rainfall variables should be included in the model. This may provide a deep understanding on how various factors affect maize (Z. mays) yields in the region. Such variables could include market access, input use, and extension services and so on. A comparison study using different type of models should be applied in the study area. The result may provide solid standing for informing policy and decisions making process which may be useful to agricultural stakeholders in improving maize (Z. mays) yield. Since, temperature and rainfall variables have impact on maize (Z. mays) yields in the region, the government through the responsible ministry should insist in conducting research frequently in order to come up with suitable maize (Z. mays) varieties that maximize yield in the region.

\section{ACKNOWLEDGEMENT}

The authors would indeed like to express their sincere gratitude to the Tanzania Meteorological Agency (TMA) and the Ministry of Agriculture, Livestock and Fisheries (MALF) for their support on data provision.

Open Access: This is an open access article distributed under the terms of the Creative Commons Attribution 4.0 License, which permits unrestricted use, distribution, and reproduction in any medium, provided the original author(s) if the sources are credited.

\section{REFERENCES}

AGPTAP, Agriculture Global Practice Technical Assistance Paper (2015). Tanzania: Agricultural sector risk assessment. Washington, USA. pp. 22-23. Retrieved from http://www.worldbank.org

Alauddin, M. and Nghiemb, H.S. (2010). Do instructional attributes pose multicollinearity problems? An empirical exploration. Economic Analysis and Policy, 40:351- 362.

Baijukya, F., Wairegi, L., Giller, K., Zingore, S., Chiwoko, R. and Mapfumo, P. (2016). Maize- Legume Cropping guide. Africa Soil health Consortium, Nairobi, pp. 4-6. Retrieved from http:// africasoilhealth.cabi.org

Chong, H.Y. (1993). Use and effectiveness of navigational aids in hypertext. A Thesis Submitted to the Graduate Faculty in Partial Fulfillment of the Requirements for the Degree of Master of Education. University of Oklahoma Graduate College, pp. 17 -18. Retrieved from http://www.creative-wisdom.com/education/thesis/thesis.PDF

Commuri, P.D. and Jones, R.D. (2001). High temperatures during endosperm cell division in maize: a genotypic comparison under in vitro and field conditions. Crop Science, 41: 1122- 1130.

Garson, G.D. (2012). Testing Statistical Assumption. North Carolina State University School of Public and International Affairs. Statistical Associates Publishing, USA. pp. 42-43.

Gelfand, S.J. (2013). Understanding the impact of Heteroskedasticity on the predictive ability of morden regression methods. Dissertation submitted in partial fulfillment of the requirements for the degree of Master of Science in the department of statistical and actuarial science, faculty of science. Simon Fraser university, Canada, pp. 4-5.
Haji, S.J. (2013). Assessment of Effects of Climate Variability on Maize Production in Mbeya Region. A Research Project submitted in Partial Fulfillment of the Requirement for the award of Postgraduate Diploma in Meteorology. Department of Meteorology, University of Nairobi, pp 26-32.

Hawking, R.R. and Pendleton, O.J. (1983). The regression dilemma. Communication in Statistics- Theory and Methods, 12: 497-527.

Jones, J.W., Hoogenboom, G., Porter C.H., Boote, K.J., Batchelor, W.D., Hunt L.A., Wilkens P.W., Singh, U., Gijsman, A.J. and Ritchie, J.T. (2003). The DSSAT cropping system model. European Journal of Agronomy, 18: 235-265, https://doi.org/10.1016/S1161-0301(02)00107-7

Lema, A.A., Munishi, L.K. and Ndakidemi, P.A. (2014). Assessing vulnerability of food availability to climate change in Hai District, Kilimanjaro Region, Tanzania. American Journal of Climate Change, 3: 261-271, https://doi.org/10.4236/ajcc.2014.33025

Lobell, D.B. and Burke, M.B. (2010). On the use of Statistical models to predict crop yield responses to Climate change. Agriculture and Forest Meteorology, https://doi.org/10.1016/j.agrformet.2010.07.008

Lobell, D.B. and Field, C.B. (2007). Global scale climate - crop yield relationships and the impacts of recent warming. Environmental Research Letters, 2: 1-7.

Lobell, D.B., Schlenker, W. and Costa-Roberts, J. (2011). Climate trends and global crop production since 1980. Science, 333: 616-620, https://doi.org/10.1126/science.1204531

Luhunga, P.M. (2017). Assessment of the impacts of climate change on maize production in the southern and western highlands sub-agro ecological zones of Tanzania. Retrieved from https://www.researchgate.net/publication/264219739

Mndeme, F.G. (2016) Adaptation strategies to climate variability and climate change; Impacts on food security among smallholder farmers in Moshi Rural District, Kilimanjaro Region, Tanzania: Perceptions, Capacities and Limitations of adaptive strategies. Master Degree Programme in Agro-Environmental Management. Department of Agroecology-Faculty of Science and Technology, Aarhus University, Denmark, pp. 74-76.

Majule, A.E. (2015). Climate change risk on agriculture and response strategies by small holder farmers in Lake Victoria Basin, Tanzania. World Journal of Agricultural Sciences, 3 (3): 38- 49.

Mongi, H., Majule, A.E. and Lyimo, J. G. (2010). Vulnerability and adaptation of rain - fed Agriculture to climate change and vulnerability in semi-arid Tanzania. African Journal of Environmental Science and Technology, 4: 371-381.

Mooi, E. and Sarstedt, M. (2011). A concise guide to market research: The process, data, and methods using IBM SPSS Statistics. New York: Springer. Retrieved from https://doi.org/10.1007/978-3-642-12541-6

Mtongori, H.I., Stordal, F., Benestad, R.E., Mourice, S.K., Pereira-Flores, M.E. and Justino, F. (2015). Impacts of climate change and farming management on maize yield in southern Tanzania. African Crop Science Journal, 23(4): 399 -417.

Osborne, J. and Waters, E. (2002). Four assumptions of multiple regressions that researchers should always test. Practical Assessment, Research \& Evaluation, 8(2): 1-5.

Rowhani, P., Lobell, D.B., Linderman, M. and Ramankutty, N. (2011). Climate variability and crop production in Tanzania. Agricultural and Forest Meteorology, 151: 449-460.

Schlenker, W. and Roberts, M.J. (2009). Nonlinear temperature effects indicate severe damages to U.S. crop yields under climate change. Proceedings of the National Academy of Sciences, 106: 15594-15598.

Shapiro, S.S. and Wilk, M.B. (1965). An analysis of variance test for normality (complete samples), Biometrika, 52: 591-611.

URT, United Republic of Tanzania (2014). Ministry of Agriculture, Food Security and. Cooperatives. Agriculture Climate Resilience Plan 2014- 2019, pp. 12 -15.

United Republic of Tanzania (2007). National Sample Census of agriculture 2002/2003.Volume VI: Regional Report: Mbeya region, pp. 40-42, Retrieved from http://www.tzonline.org/pdf/Mbeyareg.pdf

United Republic of Tanzania (URT) (2016). President's Office Region Administration and Local Government Mbeya Region: A brief about Mbeya region and round potato subsector given to Netherland potato trade Mission, pp. 2.

Vaughan, T.S. and Berry, K.E. (2005). Using Monte Carlo techniques to demonstrate the meaning and implications of multicollinearity. Journal of Statistics Education, 13(1): https://doi.org/10.1080/10691898.2005.11910640

White, J.W. Hoogenboom, G., Kimball, B.A. and Wall, G.W. (2011). Methodologies for simulating impacts of climate change on agricultural production. Field Crops Research, 124: 357-368, https://doi.org/10.1016/j.fcr.2011.07.001 